the patient. His purpose, whatever the disability, is to improve the quality of that life and to alleviate the burden-not to end that life by failing to give appropriate treatment or even more so by direct action to terminate that life. An important guiding principle for those doctors proposing active treatment is that the therapy should not be disproportionately burdensome to the patient, taking into account the benefit which might be expected.

Most doctors are only too aware of their own fallibility in prognosis. I well remember a child of nine months of age whose abdomen was full of tumour at the time of operation and I could do nothing. I went round to the mother's house and told her the outlook was hopeless, and that I did not expect him to live for more than a very few weeks. That was 18 years ago and he is very well. A newborn baby had a bowel obstruction and at operation the entire small intestine was black. To remove it all would be certain to lead to the child's eventual death in spite of perhaps weeks or even months of intravenous feeding. I removed most of the small intestine, but left a small portion at the upper end, near the stomach, and a similar portion at the lower end, near the large bowel. I thought the outlook was hopeless. To my astonishment, these portions of bowels survived and eventually were sufficient to maintain adequate nutrition of the baby.

The point I am making is that, even to the most expert doctors, it is not as easy as many patients or many parents think to give a clear idea of the outcome, and doctors have a duty not to give up too easily.

It is now appropriate to consider in more general terms the responsibilities of the doctor in treating seriously ill patients, especially those in whom recovery is likely to leave residual disability, of greater or less degree. It should be said at the outset that most doctors realise full well that they are not called upon to prolong the process of dying, but this clearly implies that death is imminent and inevitable. It certainly should not apply where death from the disease can be prevented, or the patient's condition improved even for a number of months.

There is a tendency to rely on totally different criteria in management of the newborn from those which are accepted in an adult. Many an adult has treatment, medical or surgical, for conditions which can be alleviated but not cured, and in which there may be considerable residual disability, whereas a rather more selective approach is now being used in the management of similar conditions in infancy. One has only to think of the contrast in the attitude among some doctors between the management of an adult with paralysis of the lower limbs, following a fracture of the spine, and a baby born with spina bifida who has a similar type of paralysis. Nor does the discrimination against the newborn stop there. Not only are a number of such babies denied ordinary, good baby-care, but many have been put on a regime of hypnotic drug therapy and underfeeding so that they will die, a practice which would cause an uproar if applied to adults.

Perhaps the most serious aspect of this regime is the deception of parents. They are told the baby will die without operation and that he will have a little sedative to make his short life easier. Yet, with ordinary, good baby-care, even without operation, it is by no means certain that the child will die and the sedative, which is ostensibly given to relieve pain, is not a pain-relieving drug but a hypnotic drug which is given for the purpose of ensuring that the child will die. Parents are not told this.

Here we have the other side of the important aspect of communication between the doctor and the parents. It is not even enough for the doctor to say words which are true. The information he gives to the parents should be put in such a way that what the parents understand is true; and if this does not happen the doctor is failing in his duty. It is wrong for the doctor to give hypnotic drugs in order to accomplish the death of an infant, even though he thinks the residual disability will make 'life not worth living'. It is also wrong for him to deceive the parents into thinking that their child is dying spontaneously.

On the other side of the coin, the doctor is not justified in telling the parents untruths; that the prognosis is good, when in fact it is bad, and it is almost as bad to leave parents in ignorance, as apparently happened to the Stinsons.

The doctors must have thought that their strenuous efforts were not disproportionate to the chances of success and the degree of improvement to be expected, and they must have judged that in the circumstances they were not unduly burdensome to the patient. I think we ought to give them credit for this at least, and if only they had taken the parents into their confidence and not only told them what they, the doctors, believed to be true, but told it in such a way that what the parents understood was true, the letter from the parents to the Hospital Administrator could have been very different.

\section{Commentary 2}

A G M Campbell Department of Child Health, University of Aberdeen

D J Cusine Lecturer in Private Law, University of Aberdeen

Unfortunately, this experience is not unique to the Stinsons. It is not unique to this particular 'Pediatric Hospital Center' (PHC) intensive care unit and, perhaps with the exception of the financial cost, it is not unique to the United States. What is unusual, if not unique, is that the Stinsons had the courage 
and ability to describe, movingly and with devastating accuracy, the agonising dilemmas that face parents and doctors who get caught up in these tragedies of modern medicine. The Stinsons expose what might be called 'the darker side' of modern newborn intensive care.

\section{What went wrong?}

Why were the Stinsons left with such a deep sense of resentment towards this hospital and its staff, the doctors in particular? What went wrong at PHC? What was missing? Of course, there is much to deplore in what happened, but in our view, the root cause was lack of medical leadership. With modern treatments more and more infants are surviving at 'the extreme margin of human viability' and with other complex problems but it should be emphasised that the majority of these very low birth weight infants can be protected successfully against potentially brain-damaging complications. They will grow to be healthy and their parents will be grateful. Technical advance thrives on success. For a few, the treatments will fail eventually, or the infants will survive with severe and permanent impairment. It is much more difficult to develop equivalent strategies to cope with failure. Between parents and doctors withdrawal of contact, distrust, suspicion, alienation and lasting bitterness may result from the experience.

In the complex and frightening world of the intensive care unit parents feel helpless to aid and love their infant and frustrated in their inability to influence decisions that they think are wrong or do not understand. Their views may be ignored or not even sought. In medical decisions, it seems to them, technical considerations are paramount and overrule all others. What they view as 'bad decisions' may be supported by other doctors, by the hospital administration and even by the courts. As time goes by they see for themselves the decline of the life-enhancing benefits of modern medicine that may have raised hopes at first; they become aware of the distressing complications of aggressive intensive care, and they witness the dehumanising indignities of total life support. Above all they begin to understand the dread implications of 'brain damage' and what that may mean for their child and their family. As the Stinsons have detailed, the physical, emotional and financial costs can be catastrophic.

\section{The newborn intensive care nursery}

It would be wrong to assume that this scenario of human and medical failure is commonplace in intensive care nurseries. Far from it, it need not be like this. In many units through appropriate leadership the staff have evolved a philosophy of care that includes paying particular attention to the needs of parents-for information; for counselling; 志r discussion and questions; for emotional whd financial support. $(I, 2)$ Parents are encouraged to visit regularly so that through familiarity with and involvement in various aspects of the care of thäeir baby, they are relieved of much of the fear with which they first view an intensive care nursery. 다 is obvious that the concentrated, intimate, soceial interactions between personnel, infants and parsists in an emotionally charged atmosphere often make the work of the staff very difficult and demanding However, such participation and recognition of parents' rights to information about their infant appear to be the chief foundations of informed consent for treatment.' (3)

Perhaps one of the saddest aspects of the Stinsons' experience was the perceived insensitivity and callousness of most of the doctors involved. It is unlikely that the doctors at PHC were any dess sensitive, more callous, or in other ways different from doctors elsewhere. Yet they seemed like that to the Stinsons who recognised that 'the residents themselves were victims of a rotation system whifch prevents an individual doctor from providing continuity of care and from developing a supporope relationship with the family.' The junior doctors deserve our sympathy. They, like the Stinsons ond their baby, were victims of the system. It is not essy to provide intensive care. (4) We suspect that it is क्.he most demanding of all hospital services physic@lly and emotionally. Recognition of the adverse effects of such an environment on doctors and nurses Fas been slow. The pressures are intense and are becoming worse. Staffing levels have not kept psice with the burgeoning demand and the increasing complexity of care. A condition affecting newborn intensive care unit workers known as 'burnout' has been described and defined as 'the loss of mot tion for creative involvement.' (5) There can be a devastating effect on physical health, on the emotions and on behaviour which may become quite bizarre and out of character. It is 'expressed as having little energy, questioning the value one's efforts, or as feelings of "who gives a damn anyway?" Hostility and negativism emerge and gre directed at fellow workers, the unit, or patients or their families.'

\section{Leadership}

To avoid or minimise these serious problems strong but responsive leadership is essential. ?n Andrew Stinson's case nobody seemed to be Tn charge. Nobody became his doctor and assumed responsibility for his care and for attending to his parents' needs. We are told that 'one resident fos an unusually (our italics) understanding persen who was willing to remain in contact with us and with Andrew's case for all the months which followed his official tour of duty in the ICU.' It should 
not have been left to one understanding resident to provide all the continuity and compassion that the Stinsons feel they received during a period of six months. The Stinsons were told that 'continuity was assured' by the presence of the intensive care unit's three attending physicians but 'they rotated too and it was common knowledge that the philosophy of neonatal care varied from one attending doctor to the next.' Chaos, confusion and conflict are the almost inevitable consequences of such an arrangement. Junior doctors and the nurses will be left to get on as best they can.

The complexity of modern newborn intensive care (and other forms of intensive care) demands the participation and teamwork of a large group of individual personalities with different degrees of knowledge, competence, experience, sensitivity and judgement. They will have differing views on purely technical matters quite apart from widely varying opinions on ethics and the law. With this kind of mixture strong leadership and 'team spirit' are absolutely critical. One doctor must assume responsibility and leadership of the clinical team caring for an individual infant. He or she will be primarily responsible for making decisions in management, for coordinating the advice and activities of other specialists and, most important, for keeping the parents informed about all aspects of care and the infant's condition. Of course, it is impossible for one individual to be available continuously but with leadership, sharing of information and appropriate delegation good communication and understanding can be maintained. Regular 'up-dating' discussions can be held to include nurses, social workers and other family members as appropriate. If team morale is to be maintained all must work together in a common purpose and to consistent policies.

\section{Philosophy of neonatal care}

What about the variation in the 'philosophy of neonatal care' from one doctor to another? The Stinsons indicate the conflicts that can arise when physicians fail to make difficult decisions or make choices that are inconsistent with each other or with the parents' views. It may be a matter of chance if parents encounter a doctor who is sensitive to their views and to their wishes. They may encounter a doctor who at one extreme will abrogate his responsibility completely in making difficult decisions or at the other will exercise excessive authority by presuming that he alone must decide what is best for his patient. Either way the parents will feel isolated and helpless. Parents have a right to participate in decisions about their infants and doctors should respect this right. The importance of informed consent for treatment is generally accepted. We should recognise that parents may have a right to informed dissent. Veatch's description of the doctor-patient relationship as the 'contractual model' (6) can be applied to infants and children under the age of consent when parents and physicians share ethical authority and responsibility. 'The basic norms of freedom, dignity, truth-telling, promise-keeping and justice are essential' to this relationship. If either party finds the terms contrary to his conscience he may reject or break the contract. In acknowledging that there are limitations to professional autonomy and power, doctors should show more humility and be prepared to question the 'correctness' of their decisions for individual families, particularly where the application of modern technology is concerned. As the Stinsons express it, 'there is a moral and ethical problem of the most fundamental sort involved in a system which allows complicated decisions of this nature to be made unilaterally by people who do not have to live with the consequences of their decision'. It seems to us that doctors have a primary responsibility to help patients, parents and families cope with the injustices of disease and disability. Perhaps we should also recognise more openly the hypocrisy and lack of natural justice that are inherent in some current policies and trends through individual notions of morality and fear of the law. $(7,8)$ The Stinsons point out that 'the situation now exists in which it is very easy to turn on a respirator no-one's consent is even needed-and almost impossible to turn one off'.

At this point it might be useful to review some of the legal issues raised by this case and attempt to clarify the current legal position both in the UK and the USA.

\section{Children and consent}

There is no doubt that infants are unable to give consent and therefore it must be obtained elsewhere. There are several persons who may be intimately involved with the child and who may therefore be thought able to give the necessary authorisation. These are the parents or guardians, those responsible for the provision of the medical care and the State (acting through the courts).

Where the child has a parent and it is not disputed that the proposed treatment is in the best interests of the child legal problems are unlikely to arise. Complications may occur where the child does not have a parent, or the parents are unable to give consent, or they refuse to give consent, for example, for religious reasons or because, as in the Stinson case, they do not accept that the proposed treatment is in the best interests of the child.

USA

As in many fields of law, parental refusal to give consent has been considered more fully in the USA than in the UK. In the USA, the State has 
power to protect the welfare of children, but if that power is exercised in spite of objections by the parents on grounds of religion or conscience, it might be thought that this is unconstitutional, since these freedoms are enshrined in the First Amendment to the US Constitution. However, following guidelines by the US Supreme Court, it has been held that the exercise of this power does not violate the Constitution. There have been a number of cases, (9) and the courts seem to be adopting a protective rôle, not only when the child's life is threatened, but also in other circumstances if they consider that to be in the child's best interests. (IO)

\section{UNITED KINGDOM}

Although there has been no reported decision in the UK on parental refusal to give consent, there are a number of factors which assist any attempt to formulate the legal position. Firstly, there is legislation (II) against the wilful neglect of children which includes deliberate or reckless failure by a parent to supply medical aid. (12) Secondly, where parents disagree on any question affecting the child's welfare, a court may adjudicate on the matter as it thinks proper. (13) These and many other examples demonstrate that the courts do have a protective rôle and that it will be exercised as the court thinks fit. There seems little doubt that a court in the UK would overrule parental objection, at least for necessary treatment, and this was done in 1973 in Scotland by a sheriff who granted permission for a child to have a blood transfusion. (14)

The Stinsons seemed to feel that they were best able to represent their child and hence that their views should have prevailed, but while one may have a great deal of sympathy with that view in the particular circumstances, the parents will not automatically prevail and if the matter is brought to court, the court may well overrule the parents in the interests of the child.

If the problem in the Stinson case had been simply that of the parents withholding consent, the hospital staff could have ignored that if there had been an emergency, or they might have decided to ignore the parental opposition on the basis that the parents were incapable of making a rational decision, or that in the doctors' clinical judgement further treatment was necessary and that the advantages outweighed the 'fault' of proceeding without consent. It is, however, risky to ignore parental objections except in an emergency and the matter should have been referred to the courts. The need for such a referral is more apparent when one recognises that the Stinson case also raises the question of quality of life.

\section{Euthanasia and letting infants die}

There has been considerable debate among phil- osophers as to whether there is an ethical distinction between taking active steps to kill a patient, and $\underset{F}{F}$ withholding treatment which accelerates the patient's death (15) but in law, a distinction would : be drawn between a doctor taking these active $\overrightarrow{\vec{ज}}$ steps and one who has done all that he reasonably $\overrightarrow{0}$ can to prevent the patient dying and decides to do 흠 no more, or with the patient's consent, takes no $\frac{\overline{\bar{s}}}{\overline{2}}$ further steps. There would not be any legal liability $\mathbb{\phi}$ for a failure to act unless there was a duty to act in the first place. (I6)

If, therefore, a doctor allows a defective newborn $\vec{\circ}$ to die, the question is whether there was a legal duty $\overrightarrow{\vec{\omega}}$ to provide treatment which was withheld. It has $\stackrel{\sigma}{\omega}$ been suggested that the practices described by $\overline{\overline{3}}$ Duff and Campbell (3) would be a violation of the criminal law in almost every State in the USA, (17) but this assumes that there was a legal duty which $\vec{\omega}$ was not discharged. In the UK, the corresponding 0 provisions deal with 'neglect' and it is submitted that if a doctor has done all that was reasonable in $\vec{z}$ the circumstances, it is not neglect, and hence not a breach of duty, to allow an infant to die. As one $\stackrel{\rho}{工}$ distinguished legal writer has put it, 'All that a $\vec{\bullet}$ doctor must positively do for his patient is to supply $\infty$ the service and care that are customarily expected of a doctor; and this does not involve him in an unlimited obligation to fight a hopeless battle.' (I8)

Naturally, there will be cases in which there is dispute and in the Stinson case the parents and doctors differed on whether everything reasonable $\stackrel{\square}{\square}$ had been done. The doctors seemed convinced that $\overrightarrow{\overrightarrow{0}}$ there was some hope that the child could lead a 3 normal existence, but one suspects that that hope diminished as time went on and perhaps there should have been a complete reconsideration of the child's condition and its prognosis. (However, the doctors might have been unwilling to admit defeat or they might have feared prosecution if they withheld treatment).

A case which gives some guidance is that of Karen Quinlan (I9) whose father was permitted by a US court to exercise her right to refuse further treatment if the doctors considered that further efforts on their part would be of no avail. (20) Given the unwillingness of the doctors to comply with what the Stinsons wanted, the latter should have taken the issue to court.

It has been said (2I) that doctors do not like the adversary nature of court proceedings nor the public exposure of their attitudes and practices, but while one may sympathise with that view, it may be desirable for these issues to be ventilated in the courts. Firstly, the courts may adjudicate somewhat more dispassionately than the doctors or the parents. Secondly, the State has an interest in the fate of patients, particularly where the doctors and the patient/relatives cannot agree on what to do and neither is prepared to yield. Perhaps the strongest argument is that judicial decisions may

.


introduce some certainty into the doctor's legal position. A doctor may be apprehensive about doing what he considers 'right' because he fears prosecution or civil action. A court decision may not be in his favour and he may continue to act according to the dictates of his conscience, but that decision has the advantage of assuring others that their activities do not contravene the law.

However, one other argument is advanced for not involving the courts, viz. that they have tended to favour life without regard to its quality. Even if that is admitted, it does not follow that the courts will continue to adopt this approach and there is a recent example of a US court upholding a decision to withhold treatment. In Superintendent of Belchertown State School v. Saikewicz (22) the guardian of a severely retarded and terminally ill man decided that the man should not be treated and this was upheld by the Massachusetts Supreme Judicial Court. Because of the importance of the issue, the court's judgement has attracted considerable comment both favourable and unfavourable (23) which it is not possible to summarise here. What the court did was to assert the right of all patients, including incompetents to decline potentially life-prolonging treatment, but in reaching its decision, the court said that it must try to establish the wishes of the particular patient and in the case of an incompetent patient, he should be compared to a competent patient who is advised of his position. However, in a somewhat unclear statement the court said that the subjective consideration of the 'quality of life' was not a proper basis on which to reach a decision. In Saikewicz it made no difference to the decision, but it leaves unsettled the whole question of 'quality of life', especially in relation to defective newborns. As one observer put it, (24) 'This ruling could mean that brain damage to an infant, or very serious burns and disfigurement and limited bodily functioning, could not be taken into consideration in offering or withholding resuscitation or intensive care to a patient.' One last aspect of the decision which requires comment is on the procedure in such cases. In effect, the court decided that a decision to treat or not to treat was for the court to make and not for any other group. While we have advocated that, in cases of dispute, the issue should be resolved by the courts, few would advocate that this should be done in every case. It is to be hoped that this latter aspect of the court's decision will be reconsidered and that other courts will not follow it. In the Quinlan case, the court left the decision with the family, the doctors and the hospital ethical committee and it is not possible to reconcile that with Saikewicz nor with subsequent decisions. (8)

While the courts have had relatively few opportunities to pronounce upon these issues, there have been long-standing moves to have legislation on 'euthanasia', particularly in its active form, but so far, none has been successful. (25) The law in most countries prohibits anyone taking active steps to hasten death, but it is in a state of uncertainty on the issue of withholding treatment. Until the courts or the legislatures clarify matters, decisions must continue to be made by doctors and patients and, in the case of very young children, the parents. It would be safer and may indeed be advantageous where the doctors and the others involved cannot agree, for the courts to be asked for a decision, even if such decisions do not resolve all the issues.

\section{References}

(I) Jonsen A R, Phibbs R H, Tooley W H, Garland $M$ J. Critical issues in new-born intensive care: a conference report and policy proposal Pediatrics 1975; 55: 756-768.

(2) Duff R S. Guidelines for deciding care of critically ill or dying patients. Pediatrics 1979; 64: 17-23.

(3) Duff R S, Campbell A G M. Moral and ethical dilemmas in the Special Care Nursery. New England journal of medicine 1973; 289: 890-894.

(4) Frader J E. Difficulties in providing intensive care. Pediatrics 1979; 64: 10-16.

(5) Marshall R E, Kasman C. Burnout in the neonatal intensive care unit. Pediatrics 1980; 65: Ir6I-1165.

(6) Veatch R M. In: Hastings Center Report, Volume 2. New York: Hastings-on-Hudson, 1972.

(7) Duff R S, Campbell A G M. Moral and ethical dilemmas: Seven years into the debate about human ambiguity. Annals of the American Academy of Political and Social Science 1980; 447: 19-28.

(8) Paris J J. Court intervention and the diminution of patients' rights: The Case of Brother Joseph Fox. New England journal of medicine 1980; 303: 876-878.

(9) Prince v. Massachusetts 32I U.S. 158; 64 Sup. Ct. 784 (1944); People ex rel Wallace v. Labrenz 4I I III 618; 104 NE. 2d 769 (1952); In re Seiferth 309 NY. 80; 127 NE. 2d 820 (1955); In re Clark 185 NE. 2d 128 (1962).

(I0) In Re Sampson 29 NY. 2d. 900; 328 NYS. 2d. 686; 278 NE. 2d. 918 (1972).

(II) Children \& Young Persons Act 1933 as amended (England \& Wales); Children \& Young Persons (Scotland) Act 1937 as amended.

(I2) $R$ v. Senior [1899] I Q.B. 283; $R$ v. Lowe [1973] I Q.B. 702.

(13) Guardianship Act I973 s. I (England \& Wales); sio (Scotland).

(I4) Sheriff allows blood for baby. The Scotsman 1973; April 25: I

(I5) Fletcher J. Moral responsibility; situation ethics at work, Philadelphia, Westminster Press 1967 p 150, argues that there is no distinction; also see Audi R. The Moral Rights of the Terminally Ill. In Davis J W, Hoffmaster B, Shorten S, eds. Contemporary issues in biomedical ethics Clifton, New Jersey: The Humana Press Inc, 1978.

(16) Williams G. Textbook of criminal law, London: Stevens \& Sons Ltd. 1978: 233-237; Robertson J A. Discretionary Non-Treatment of Defective New- 
borns. In: Milunsky A, Annas G J, eds. Genetics and the law, New York: Plenum Press, 1976.

(I7) Robertson J A. Involuntary Euthanasia of Defective Newborns. Stanford Law Review 1975; 27: 213269; Robertson J A, Fost N. Passive Euthanasia of Defective Newborn Infants: Legal and moral considerations. Fournal of pediatrics $1976 ; 88: 883-$ 889.

(18) Williams G. Euthanasia, Medico-Legal fournal 1972; 4I: 19.

(19) Quinlan J, Battelle P. Karen Ann. London: Proteus, 1978.

(20) ReQuinlan 70 NJ 10; 355 A 2d 647 (1976).

(2I) Duff R S, Campbell A G M. On deciding the care of severely handicapped or dying persons: with particular reference to infants Pediatrics 1976; 57 : 487-493. Also Campbell A G M, Duff R S. Deciding the care of severely malformed or dying infants. Fournal of medical ethics 1979; 5: 65-67.

(22) 370 NE. 2d. 4I7 (1977).

(23) Keyserlingk E W Sanctity of life or quality of life. Montreal: Law Reform Commission of Canada: Protection of Life Series, 1979. Ramsey P. The Saikezvicz Precedent: What's Good for an Incompetent Patient? Hastings Center Report 8 1978; 6: 36-42. Curran W J. The Saikewicz Decision. New England journal of medicine 1978; 298: 499- 50r. Relman A S. The Saikewicz Decisiom: Judges as Physicians New England journal of medi cine 1978; 298; 508-509. Annas G. After Sailewicz: No Fault Death, Hastings Center Report $; 8$ 1978; 3: 16-18.

(24) Curran op. cit. p 500. See above (23).

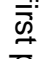

(25) The Voluntary Euthanasia Legalisation Socigy was formed in England in 1936 and presentech:a Bill in the House of Lords in the same year. H.I. Deb. 103, 465-506 (1936). In a Debate in 1950, only 4 members spoke in favour of legalisfog euthanasia (H. L. Deb. 169, 551-76) (1950). Two further attempts were unsuccessful viz: The Voluntary Euthanasia Bill and the Incurable Patients Bill 1975. In the USA, the Euthanasis Society of America was formed in 1938 and 1 it adopted the English Bill as its model, but it faifed in both the Nebraska and New York Assemblines. Since then little has altered except that under the California Natural Death Act 1976, an addolt person of sound mind may direct a physiciancto withdraw or withhold 'life sustaining procedures' when the patient has a 'terminal condition'. Fona fuller discussion see Meyers, D W (1978) Timenof Death-Medico Legal Considerations in Americann furisprudence: Proof of Facts 2nd Series New Yonk: The Lawyers Coperative Publishing Col.; \$8n Francisco: Bancroft-Whitney Co. S. 6. 